\title{
Pemberdayaan Masyarakat Desa Pangi Dalam Pengolahan Limbah Organik Dan Anorganik
}

\author{
Wiwin Rewini Kunusa, Hendri lyabu \\ Jurusan Kimia, Fakultas Matematika dan Ilmu Pengetahuan Alam, Universitas Negeri Gorontalo \\ Email: rewinikunusa2014@gmail.com; +62823-4732-8886
}

\begin{abstract}
Abstrak
Kegiatan pengabdian kepada masyarakat merupakan salah satu Dharma Perguruan Tinggi. Kegiatan ini dapat dinilai sebagai salah satu tugas bagi lembaga, para dosen, dan para mahasiswa. Melalui program kegiatan KKN-PPM 2020 akan dilakukan suatu kegiatan tentang limbah organic dan anorganik di Desa Pangi Kecamatan Dulupi Kabupaten Boalemo. Limbah organic berupa ampas sagu yang berasal dari pabrik pengolahan sagu dan limbah plastik rumah tangga. Tujuan dari kegiatan ini adalah (1) mengolah limbah padat sagu menjadi briket sebagai bahan bakar alternatif pengganti gas elpiji (2) Daur ulang sampah plastic menjadi berbagai kerajinan tangan yakni aksesoris yang bernilai ekonomis. Sasaran kegiatan adalah untuk memberdayakan masyarakat Desa Pangi khususnya Ibu-lbu PKK dan Karang Taruna dalam mengolah limbah organic dan anorganik untuk meningkatkan keterampilan dan perekonomian ibu-ibu rumah tangga. Mekanisme pelaksanaan dalam bentuk penyuluhan dan pelatihan selama 45 hari. Lokasi pelaksanaan di Dusun Mootilango, Tibawa dan Bongo Ngoayu yang berpusat di kantor Desa Pangi. Tahap persiapan berupa koordinasi ke Dinas/Instansi terkait dan Pembekalan Mahasiswa KKN-PPM. Pembelajaran disertai praktek dilakukan oleh dosen pembimbing, mahasiswa bersama kelompok masyarakat khususnya PKK/DasaWisma dan karang Taruna. Kegiatan ini diharapkan sejalan dengan tujuan Pemerintah Kabupaten Boalemo yakni “Menuju Boalemo Bebas Sampah". Hasil dari kegiatan ini adalah terlaksananya pengolahan limbah ampas sagu menjadi briket terlaksana dengan baik dan sampai pada taraf aplikasi ke masyarakat. Begitupun dengan pengolahan limbah plastik rumah tangga yang telah menghasilkan beberapa produk cenderamata yang menjadi ciri khas Ibu-lbu PKK dan Dasawisma Desa Pangi.
\end{abstract}

Kata Kunci : sampah plastik, ampas sagu, briket.

\begin{abstract}
Community service activities are one of the Dharma of Higher Education. This activity can be assessed as one of the tasks for the institution, lecturers, and students. Through the 2020 KKN-PPM activity program, an activity on organic and inorganic waste will be carried out in Pangi Village, Dulupi District, Boalemo Regency. Organic waste in the form of sago waste originates from sago processing factories and household plastic waste. The objectives of this activity are (1) processing sago solid waste into briquettes as an alternative fuel to replace LPG (2) Recycling plastic waste into various handicrafts, namely accessories that have economic value. The target of the activity is to empower the people of Pangi Village, especially $P K K$ and Youth Organizations in processing organic and inorganic waste to improve the skills and economy of housewives. The implementation mechanism is in the form of counseling and
\end{abstract}


training for 45 days. The location of the implementation is in Mootilango, Tibawa and Bongo Ngoayu hamlets, which is based at the Pangi Village office. The preparation stage is in the form of coordination with related agencies / agencies and provision of KKN-PPM students. Learning accompanied by practice is carried out by supervisors, students and community groups, especially PKK / DasaWisma and Karang Taruna. This activity is expected to be in line with the goal of the Boalemo Regency Government, namely "Towards a Trash Free Boalemo". The result of this activity is that the processing of sago waste into briquettes is carried out well and reaches the stage of application to the community. Likewise with the processing of household plastic waste which has produced several souvenir products that are characteristic of PKK and Dasawisma Pangi Village mothers.

Keywords: plastic waste, sago waste, briquettes.

\section{PENDAHULUAN}

Potensi Unggulan Desa Pangi, Desa Pangi termasuk dalam Kecamatan Dulupi, Kabupaten Boalemo Provinsi Gorontalo berada $\pm 130 \mathrm{~km}$ dari lbu Kota Provinsi, terdiri dari 3 dusun: Dusun Mootilango, Tibawa dan Bongo Ngoayu jumlah KK 405, KK 432 dan KK 592. Total jumlah penduduk 1441 orang. Desa Pangi sebagai salah satu kawasan pengembangan Ketahanan Pangan Nasional di Kabupaten Boalemo yakni sebagai daerah penghasil sagu dengan area $\pm 24,657 \mathrm{Ha}$ yang menjadi sumber penghasilan masyarakat $\pm 20 \%$. Desa ini juga merupakan penghasil sagu dengan produksi sagu mencapai \pm 20 ton/minggu. Proses pengolahan sagu menghasilkan limbah, baik limbah padat maupun limbah cair yang cukup mencemari lingkungan sekitar. Limbah pertanian ini merupakan salah satu alternatif yang bisa diterapkan dan dikembangkan. Ketersediaan bahan baku yang melimpah dan belum dimanfaatkan perlu diperhatikan untuk meningkatkan nilai ekonomis limbah.

Ampas sagu merupakan salah satu limbah yang dapat dioleh sebagai energy terbarukan oleh karena energy yang terkandung dalam limbah organic padat dapat dimanfaatkan melalui pembakaran langsung atau mengkonversikannya dalam bentuk lain seperti briket sebagai energy alternative pengganti gas elpiji. Melalui kegiatan KKN-PPM, sinergitas mahasiswa dan masyarakat Desa Pangi, limbah padat ampas sagu diolah dan dimanfaatkan menjadi suatu produk bernilai ekonomis dan membantu meningkatkan perekonian masyarakat khususnya ibu-ibu rumah tangga. Limbah padat ampas dibuat briket dan aksesoris berupa gantungan kunci sebagai cenramata yang menjadi cirri khas Ibu-Ibu PKK dan Dasawisma Desa Pangi. Program kegiatan KKN-PPM adalah memberikan edukasi dan pelatihan kepada Ibu-ibu PKK/Dasawisma serta Karang Taruna membuat berbagai produk berbasis limbah hasil pengolahan sagu.

Briket dengan kualitas yang baik diantaranya memiliki sifat seperti tekstur yang halus, tidak mudah pecah, keras, aman bagi manusia dan lingkungan serta memiliki sifat-sifat penyalaan yang baik. Sifat penyalaan ini diantaranya adalah mudah menyala, waktu nyala cukup lama, tidak menimbulkan jelaga, asap sedikit dan cepat hilang serta nilai kalor yang cukup tinggi. Lama tidaknya menyala akan mempengaruhi kualitas dan efisiensi pembakaran, semakin lama menyala dengan nyala api konstan akan semakin baik (Hartoyo dan Roliadi, 1978). Penelitian intensif tentang briket campuran biomassa dan batubara telah dilakukan oleh beberapa peneliti (Bahillo, dkk., 2003; Saptoadi, 2004; Syamsiro, 2007).

Dari hasil pelaksanaan survey kegiatan inti mahasiswa KKN-PPM, Pengolahan sagu yang menghasilkan limbah organic baik limbah padat maupun limbah cair dari hasil pemerasan isi batang sagu yang menumpuk dan menimbulkan bau akibat reaksi asam organik 
yang terbentuk pada proses pengendapan serta limbah cair dari proses pencucian yang bersifat asam dengan konsentrasi padatan tinggi perlu diolah dan ditangani lebih lanjut. Fenomena lain yakni limbah anorganik berupa sampah plastic dengan kuantitas produksi yang cukup besar di skala rumah tangga, perlu dilakukan daur ulang sehingga termanfaatkan. Sejauh ini keterlibatan masyarakat dalam mengurangi pemakaian dan mendaur ulang plastik masih kurang. Jika pembakaran plastik tidak sempurna (di bawah $800^{\circ} \mathrm{C}$ ) dapat membentuk dioksin, yaitu senyawa yang dapat memicu kanker, hepatitis, pembengkakan hati dan gangguan system saraf (Sirait, 2009).

Menyikapi fenomena yang terjadi, upaya untuk mengatasi limbah ini memerlukan suatu pendekatan dan bahkan paradigma baru yang untuk beberapa hal berbeda dengan tindakan yang selama ini dijalankan. Perlunya suatu inovasi terutama pada ibu-ibu PKK dan dasawisma untuk mengurangi limbah rumah tangga dimulai dari pemilahan sampah organik dan anorganik. Demikian juga limbah hasil pengolahan sagu tidak lagi menjadi momok bagi masyarakat bahkan sebaliknya dapat menjadi nilai tambah dalam meningkatkan perekonomian dan menjadi ladang rezeki bagi warga sekitar. Berdasarkan uraian diatas, melalui sinergitas KKN-PPM dengan masyarakat dalam pengolahan limbah organic dan anorganik menjadi produk bermanfaat yang bernilai ekonomis sebagai tujuan dari pelaksanaan kegiatan ini. Pemberdayaan masyarakat yang berorientasi pada terberdayanya masyarakat dari aspek terciptanya lingkungan bersih serta terbukanya lapangan kerja sehingga SDA di sekitar bernilai ekonomis. Peningkatan wawasan/pengetahuan, empati/perasaan kepedulian, sikap dan perilaku masyarakat, pemberdayaan masyarakat dalam pengolahan limbah sagu serta terciptanya lapangan kerja dan peningkatan ekonomi masyarakat akan terwujud.

\section{BAHAN DAN METODE}

Tempat pelaksanaan pengabdian di Desa Pangi, Kecamatan Dulupi, Kabupaten Boalemo dan dilaksanakan selama 45 hari, mulai Tanggal 02 Juli - 17 Agustus 2020. Sampel pengabdian yakni masyarakat Desa Pangi, Kecamatan Dulupi, Kabupaten Boalemo, khususnya Ibu-ibu PKK dan Dasawisma serta Karang Taruna. Metode yang digunakan dalam kegiatan ini adalah teknik pembelajaran kelompok disertai praktek yang pelaksanaannya dibuat dalam 3 tahap yakni :

\section{A. Tahap Persiapan :}

1. Bersama mahasiswa Peserta KKN-PPM : Kegiatan pemberian teori dalam ruangan dengan materi panduan yang sudah dibagikan kepada para peserta, yaitu : penjelasan singkat proses pengolahan limbah yang ramah lingkungan

2. Penjelasan singkat proses pembuatan briket dari ampas sagu sebagai alternative energy dalam skala rumah tangga

3. Penjelasan singkat proses penanganan sampah plastik yang populer selama ini adalah dengan 3R (Reuse, Reduce, Recycle).

4. Tahap Persiapan dengan Mitra/Masyarakat Desa Pangi Lokasi KKN-PPM : Sosialisasi ke mitra dan pemerintah setempat tentang program inti maupun program tambahan dan Pertemuan dengan anggota kelompok mitra untuk jadwal-jadwal pelaksanaan program kegiatan KKN-PPM 


\section{B. Tahap Pelaksanaan Kegiatan Inti}

1. Persiapan Bahan Baku

2. Sampling lokasi pabrik oleh peserta dan Pengumpulan bahan baku tongkol jagung, ampas sagu, limbah cair sagu dan limbah plastik rumah tangga.

3. Persiapan Alat/Bahan untuk Briket (Limbah Organik)

4. Karung dan skop, Drum pembakaran untuk briket, Bahan pencampuran (kanji), Alat penghalusan/ayakan dan Alat cetak briket berupa pipa paralon

5. Persiapan Alat-Alat untuk Daur Ulang Limbah Anorganik

6. Gunting, pisau, lem tembak, mistar, penggaris, bolpoin, peniti, gantungan kunci, karton untuk pola dan berat

\section{Tahap Aplikasi}

Tahap aplikasi produk dilakukan langsung kepada masyarakat Desa Pangi Kecamatan Dulupi

\section{HASIL}

Hasil kegiatan pengabdian masyarakat di Desa Pangi, Kecamatan Dulupi, Kabupaten Boalemo dapat dilihat berdasarkan indikator keberhasilan program pengabdian yang terdiri dari 3 aspek yakni:

\section{Aspek Pemberdayaan}

Aspek pemberdayaan dilihat melalui produk briket yang dihasilkan dari limbah ampas sagu dan tongkol jagung, serta kerajinan tangan yang diperoleh dari proses pengolahan limbah plastik rumah tangga yang tidak termanfaatkan.

2. Aspek Ekonomi

Aspek ekonomi dilihat dari (1) Peningkatan nilai ekonomis dari limbah ampas sagu dan limbah plastik. (2) Membuka peluang kerja dan bisnis bagi masyarakat dengan adanya produk yang dihasilkan yakni briket dan berbagai aksesoris. (3) Meminimalisir budget ibu-ibu untuk membeli gas elpiji dengan menggunakan briket sebagai bahan bakar alternatif (4) Terbukanya peluang usaha bagi PKK untuk mempromosikan ciri khas PKK Desa Pangi berbasis limbah ampas sagu.

3. Aspek Sosial

Aspek sosial dilihat dari terjalinnya sinergitas masyarakat akan kepedulian lingkungan dan pemanfaatan limbah untuk dapat mewujudkan tujuan bersama masyarakat Desa Pangi yakni menjadikan Boalemo menjadi kabupaten bebas sampah.

\section{PEMBAHASAN}

\section{A. Pemanfaatan Limbah Ampas sagu (Metroxylon sago) menjadi Briket}

Ampas sagu (Metroxylon sago) merupakan limbah yang dihasilkan dari proses pengolahan sagu. Dalam proses tersebut diperoleh tepung dan ampas sagu dalam perbandingan $1: 6$. Ampas sagu yang dihasilkan dari proses pengolahan ini sekitar $14 \%$ dari total berat basah batang sagu (Flach, 1997 dan Rumalatu, 1981). Limbah yang dihasilkan berupa limbah padat ampas sagu hasil pemerasan isi batang sagu dan limbah cair dari proses pencucian yang bersifat asam dengan konsentrasi padatan tinggi. Limbah padat yang dihasilkan $6 x$ lebih banyak dibandingkan dengan produksi pati sagu yakni $\pm 500 \mathrm{~kg} / \mathrm{hari}$ dari produksi \pm 200 -300 ton sagu basah/hari. Akibatnya limbah ini semakin menumpuk dan menimbulkan bau yang tidak sedap disebabkan oleh asam-asam organik yang terbentuk pada proses pengendapan. Sementara untuk limbah cair, sejumlah kilang sagu disinyalir terus membuang limbah cair hasil olahan langsung ke aliran sungai dengan kebutuhan air dalam 
proses pengolahan sagu $62,5 \mathrm{~m}^{3} /$ hari. Pengolahan limbah ini perlu penanganan khusus dan diolah sehingga bermanfaat bagi masyarakat dan bernilai ekonomis. Untuk itu diperlukan sinergitas Perguruan Tinggi, Masyarakat dan Dinas-Dinas yang terkait dalam pengolahan limbah tersebut.

Proses yang dilakukan pada tahap sampling di pabrik sagu yaitu melakukan treatment sampel dengan penjemuran selama 1 minggu. Tahap selanjutnya adalah melakukan proses pengarangan atau karbonisasi dengan menggunakan drum bekas dan kedap akan udara. Setelah ampas sagu menjadi arang, selanjutnya digerus hingga halus dan kemudian diayak. Proses pembuatan briket dilakukan dengan mencampurkan arang, tepung kanji dan air Adapun untuk perbandingan pembuatan perekat $1: 10$ antara tepung kanji dan air. 100 gram tepung kanji dilarutkan dengan $1000 \mathrm{ml}$ air $(200 \mathrm{ml}$ air mendidih $+800 \mathrm{ml}$ air dengan suhu normal). Untuk perbandingan adonan menggunakan perbandingan 1:6 antara perekat dan arang. 100 gram perekat dan 600 gram arang, karena perbandingan 1:5 adonan terlalu cair sehingga sulit dibentuk dan menimbulkan pemborosan arang dan jika perbandingan 1:7 mudah terjadi keretakan karena adonan terlalu kering. Kemudian proses pencetakan menggunakan pipa PVC dengan diameter $26 \mathrm{~mm}$ dan pengempa dari kayu balok. Setelah proses pencetakan, briket dijemur hingga kering. Briket yang telah jadi kemudian di sosialisasikan kepada masyarakat. Briket tersebut dapat dimanfaatkan oleh masyarakat sebagai pengganti bahan bakar karena briket dari ampas sagu ini mempunyai daya kalor yang panas. Selain itu, dengan adanya briket dapat meningkatkan taraf ekonomi desa dan dapat mengurangi masalah lingkungan yang disebabkan oleh limbah sagu yang melimpah.

Pengolahan limbah ini, perlu adanya sinergitas dengan Program Dinas Lingkungan Hidup dan BPBD yakni Pembentukan Bank Sampah di tiap desa bekerjasama dengan pihak LP2M Universitas Negeri Gorontalo dalam Program-Program Kegiatan KKS Pengabdian ataupun Program KKN-PPM. Pemanfaatan limbah sagu sebagai bahan bakar briket, mengurangi ketergantungan penggunaan bahan bakar minyak dan kayu bakar. selain itu dapat pula dijadikan Industri rumah tangga. kegiatan para ibu PKK menekankan pada prinsip pemberdayaan dan partisipasi masyarakat lewat pemberdayaan keluarga

\section{B. Pemanfaatan Limbah Plastik Rumah Tangga menjadi Kerajinan Tangan}

Penanganan sampah plastik yang populer selama ini adalah dengan 3R (Reuse, Reduce, Recycle). Reuse adalah memakai berulang kali barang-barang yang terbuat dari plastik. Reduce adalah mengurangi pembelian atau penggunaan barang-barang dari plastik, terutama barang-barang yang sekali pakai. Recycle adalah mendaur ulang barang-barang yang terbuat dari plastik. Limbah anorganik berupa sampah plastik sulit diuraikan oleh dekomposer, diklasifikasikan dalam sampah plastik basah dan sampah kering. Sampah basah yaitu sampah basah yang mengandung bahan-bahan organik yang menempel sehingga dapat menimbulkan bau, sedangkan sampah plastik kering yaitu sampah dalam kondisi kering dan bebas bahan organik yang menempel. Membantu dalam mengurangi sampah non organik dan dapat menghasilkan produk yang unik dan bernilai jual dapat membantu meningkatkan perekonomian masyarakat sekitarnya. Sampah-sampah anorganik seperti kantong plastik, botol, sampah bungkus seperti plastik bungkus makanan, bungkus minuman serbuk, sabun cuci, kantong plastik yang berwarna-warni, untuk dijadikan hiasan seperti kelopak bunga plastic sebagai hiasan meja. Namun demikian, masih kurangnya pengetahuan dan pemahaman masyarakat tentang pemanfaatan limbah ini yang bisa didaur ulang sehingga bernilai ekonomis. Akan berdampak positif jika masyarakat menyadari akan hal ini. 
Melalui sinergitas mahasiswa dan masyarakat, perlunya sosialisasi, penyuluhan dan pelatihan-pelatihan tentang pengolahan sampah terutama kepada Ibu-ibu PKK, Dasawisma dan karang taruna Desa Pangi. Pemanfaatan limbah anorganik dalam program ini difokuskan pada strategi kreativitas mahasiswa dengan masyarakat Desa Pangi untuk dapat memanfaatkan limbah rumah tangga berupa plastik yang tidak termanfaatkan. Kegiatan ini selain untuk menanamkan kesadaran masyarakat terhadap pentingnya menjaga kelestarian lingkungan melalui pemilahan sampah anorganik serta menumbuhkan jiwa entrepreneurship pada masyarakat khususnya bagi ibu-ibu PKK agar memiliki power untuk dapat mengelola sampah menjadi sesuatu yang bernilai jual tinggi. Produk inovasi yang dihasilkan dari limbah anorganik dalam program ini seperti : berbagai aksesoris berbasis limbah plastic, vas bunga, tas kecil, bunga plastik dan bunga kertas. Beberapa produk ini bisa meningkatkan wawasan masyarakat khususnya bagi ibu-ibu PKK sebagai peluang usaha untuk meningkatkan perekonomian desa.

Setelah pelaksanaan program pengabdian masyarakat di Desa Pangi terkait dengan pengolahan limbah organic dari ampas sagu dan anorganik dari limbah plastik rumah tangga. Dilakukan proses analisis terkait dengan pemahaman masyarakat pada program pengolahan limbah yang telah dilakukan, analisis dilakukan dengan menyebarkan kuisioner atau angket pada masyarakat Desa Pangi tentang pemahaman masyarakat yang terdistribusi dalam 20 item soal. Jumlah sampel masyarakat yang digunakan dalam proses pengumpulan data yakni sebanyak 150 responden. Dari hasil analisis data, diperoleh bahwa sebanyak $80 \%$ masyarakat yang memahami proses pengolahan limbah organik dan anorganik dengan baik, sedangkan masih terdapat $20 \%$ masyarakat yang masih kurang paham untuk dapat melakukan pengolahan sampah organik dan anorganik. Untuk itu dapat dikatakan bahwa, kegiatan program pengabdian pada masyarakat Desa Pangi berhasil membuat masyarakat paham terkait dengan pemanfaatan dan cara penngolahan limbah yang tidak termanfaatkan menjadi suatu produk yang memiliki kualitas dan harga jual yang baik.

\section{KESIMPULAN DAN SARAN}

Pengolahan limbah ampas sagu menjadi briket terlaksana dengan baik dan sampai pada taraf aplikasi ke masyarakat. Begitupun dengan pengolahan limbah plastik rumah tangga yang telah menghasilkan beberapa produk cenderamata yang menjadi ciri khas Ibu-lbu PKK dan Dasawisma Desa Pangi. Target khusus yang ingin dicapai adalah menjadikan ibu-ibu PKK memiliki skills dalam mengelola limbah ampas sagu yang belum termanfaatkan dan limbah plastic rumah tanggan menjadi produk yang bernilai ekonomis.

Perlu adanya rencana lanjutan dari pihak pemerintah setempat agar bisa memfasilitasi sarana dan prasarana pembuatan briket sehingga menghasilkan suatu produk yang bisa dikelola untuk peeningkatan perekonomian Desa Pangi Kecamatan Dulupi Kabupaten Boalemo.

\section{UCAPAN TERIMA KASIH}

Penulis mengucapkan terima kasih kepada:

1) Rektor Universitas Negeri Gorontalo

2) Ketua beserta Jajaran Lembaga LP2M Universitas Negeri Gorontalo

3) Pemerintah Desa Pangi, Kecamatan Dulupi, Kabupaten Boalemo

4) PKK dan Dasa Wisma Desa Pangi

5) Karang Taruna Desa Pangi 


\section{DAFTAR PUSTAKA}

Bahillo. A., Cabanillas. P.A, Gayan. L.P., De Diego. L., Dan Adanez, J., 2003. Co-combustion of coal and biomass in FB boilers : model validation with experimental results from CFB pilot plant, Energy Agency-Fluidized Bed Conversion.

Barbora Grycova, Adrian Pryszcz, Lenka Matejova, Pavel Lestinsky*. 2018. Influence of Activating Reagents on the Porous Structure of Activated Carbon Chemical Engineering Transactions Vol. 70, 2018. ISBN 978-88-95608-67-9; ISSN 2283-9216

Flach, M., 1997. Sago palm. Metroxylon sagu Rottb. Promoting the conservation and use of underutilized and neglected crops. Rome: International Plant Genetic Resources Institute.

Hartoyo, A .dan Roliadi H., 1978. Percobaan Pembuatan Briket Arang dari Lima Jenis Kayu, Laporan Penelitian hasil Hutan, Bogor.

Rumalatu. F.J. 1981. Distribusi dan potensi pati beberapa sagu (Metroxylon sp.) di daerah Seram Barat. Karya IImiah. Fakultas Pertanian/Kehutanan yang berafiliasi dengan Fateta IPB, Bogor.

Saptoadi, H., 2004. The best composition of coalbiomass briquettes, A two day Collaboration Workshop on Energy, Environmental, and New Trend in Mechanical Engineering, Department of Mechanical Engineering Brawijaya University, Keio University.

Syamsiro, M. dan Harwin Saptoadi, 2007. Pembakaran Briket Biomassa Cangkang Kakao :Pengaruh Temperatur Udara Preheat, Seminar Nasional Teknologi 2007 (SNT 2007), Yogyakarta.

Sirait, Mita. (2009). Sulap Sampah Plastik Lunak jadi Jutaan Rupiah. B-Frist. Yogyakarta. 


\section{LAMPIRAN}

Tabel 1. Perhitungan dalam Penggunaan Ampas Sagu

\begin{tabular}{|c|l|l|c|}
\hline $\begin{array}{c}\text { Lokasi } \\
\text { pengolahan }\end{array}$ & $\begin{array}{l}\text { Volume sagu basah yang } \\
\text { diolah /hari /minggu }\end{array}$ & Limbah Padat yang dihasilkan & $\begin{array}{c}\text { Pembuatan Briket } \\
\text { dan Aksesoris }\end{array}$ \\
\hline Lokasi 1 & $\begin{array}{l}\text { Menggunakan mesin/2-3 } \\
\text { ton/hari }\end{array}$ & $\begin{array}{l}\text { limbah padat } 6 \text { x lebih banyak } \\
\text { dari produksi pati sagu yakni } \\
\pm 18 \text { ton ampas sagu } \\
\text { basah/hari. }\end{array}$ & $12 \mathrm{Kg}$ \\
\hline Lokasi 2 & $\begin{array}{l}\text { Secara konvensional/3 } \\
\text { ton/minggu }\end{array}$ & $\begin{array}{l}\text { limbah padat } 6 \text { x lebih banyak } \\
\text { dari produksi pati sagu yakni } \\
\pm 18 \text { ton ampas sagu } \\
\text { basah/hari. }\end{array}$ & $12 \mathrm{Kg}$ \\
\hline Lokasi 3 & $\begin{array}{l}\text { Secara konvensional /500 }- \\
1 \text { ton/hari }\end{array}$ & $\begin{array}{l}\text { limbah padat } 6 x \text { lebih banyak } \\
\text { dari produksi pati sagu yakni } \\
\pm 6 \text { ton ampas sagu } \\
\text { basah/hari. }\end{array}$ & $12 \mathrm{Kg}$ \\
\hline Lokasi 4 & $\begin{array}{l}\text { Menggunakan mesin/2-3 } \\
\text { ton/hari }\end{array}$ & $\begin{array}{l}\text { limbah padat } 6 x \text { lebih banyak } \\
\text { dari produksi pati sagu yakni } \\
\pm 18 \text { ton ampas sagu } \\
\text { basah/hari. }\end{array}$ & $12 \mathrm{Kg}$ \\
\hline Lokasi 5 & $\begin{array}{l}\text { Secara konvensional /1 }- \\
1.5 \text { ton/hari }\end{array}$ & $\begin{array}{l}\text { limbah padat } 6 x \text { lebih banyak } \\
\text { dari produksi pati sagu yakni } \\
\pm 6 \text { - } 8 \text { ton ampas sagu } \\
\text { basah/hari. }\end{array}$ & $12 \mathrm{Kg}$ \\
\hline
\end{tabular}

Tabel 2. Program Tambahan Kegiatan KKN PPM Desa Pangi

\begin{tabular}{|c|c|c|}
\hline Jenis Kegiatan & Pelaksanaan & Hasil \\
\hline $\begin{array}{l}\text { Membentuk Taman } \\
\text { Pengajian anak (TPQ) }\end{array}$ & $\begin{array}{l}\text { Koordinasi dengan Pemerintah Desa } \\
\text { Pangi, Ibu-lbu PKK, Takmirul masjid dan } \\
\text { Karang Taruna }\end{array}$ & $\begin{array}{l}\text { Terbentuknya TPQ } \\
\text { (Taman Pengajian } \\
\text { Alquran di } 3 \text { masjid }\end{array}$ \\
\hline $\begin{array}{l}\text { Pembuatan } \\
\text { sanitizer }\end{array}$ & $\begin{array}{l}\text { 2. Membuat handsanitizer bersama- } \\
\text { sama karang taruna dan ibu-ibu PKK }\end{array}$ & $\begin{array}{l}\text { Produk dibagikan ke } \\
\text { masyarakat }\end{array}$ \\
\hline $\begin{array}{l}\text { Mengajar di Sekolah SD } 3 \\
\text { Pangi }\end{array}$ & $\begin{array}{l}\text { Bersama dan pendampingan guru } \\
\text { dalam kegiatan mengajar disekolah }\end{array}$ & Penerapan ilmu \\
\hline Kerja Bakti & $\begin{array}{l}\text { Bersama masyarakat dalam kegiatan } \\
\text { kerja bakti }\end{array}$ & $\begin{array}{l}\text { Terjaganya kelestarian } \\
\text { lingkungan }\end{array}$ \\
\hline $\begin{array}{lr}\text { Sosialisasi } & \text { protokoler } \\
\text { kesehatan } & \text { kepada } \\
\text { masyarakat } & \\
\end{array}$ & $\begin{array}{l}\text { Bersama masyarakat dalam kegiatan } \\
\text { pembagian masker }\end{array}$ & $\begin{array}{l}\text { Tetap memperhatikan } \\
\text { protokoler kesehatan }\end{array}$ \\
\hline $\begin{array}{l}\text { Penyemprotan } \\
\text { desinfektan }\end{array}$ & $\begin{array}{l}\text { Bersama masyarakat dan Pemerintah } \\
\text { Desa melakukan } \\
\text { penyemprotan masal terkait dengan } \\
\text { penyebaran wabah covid-19 }\end{array}$ & $\begin{array}{l}\text { Terjaganya kelestarian } \\
\text { lingkungan }\end{array}$ \\
\hline
\end{tabular}



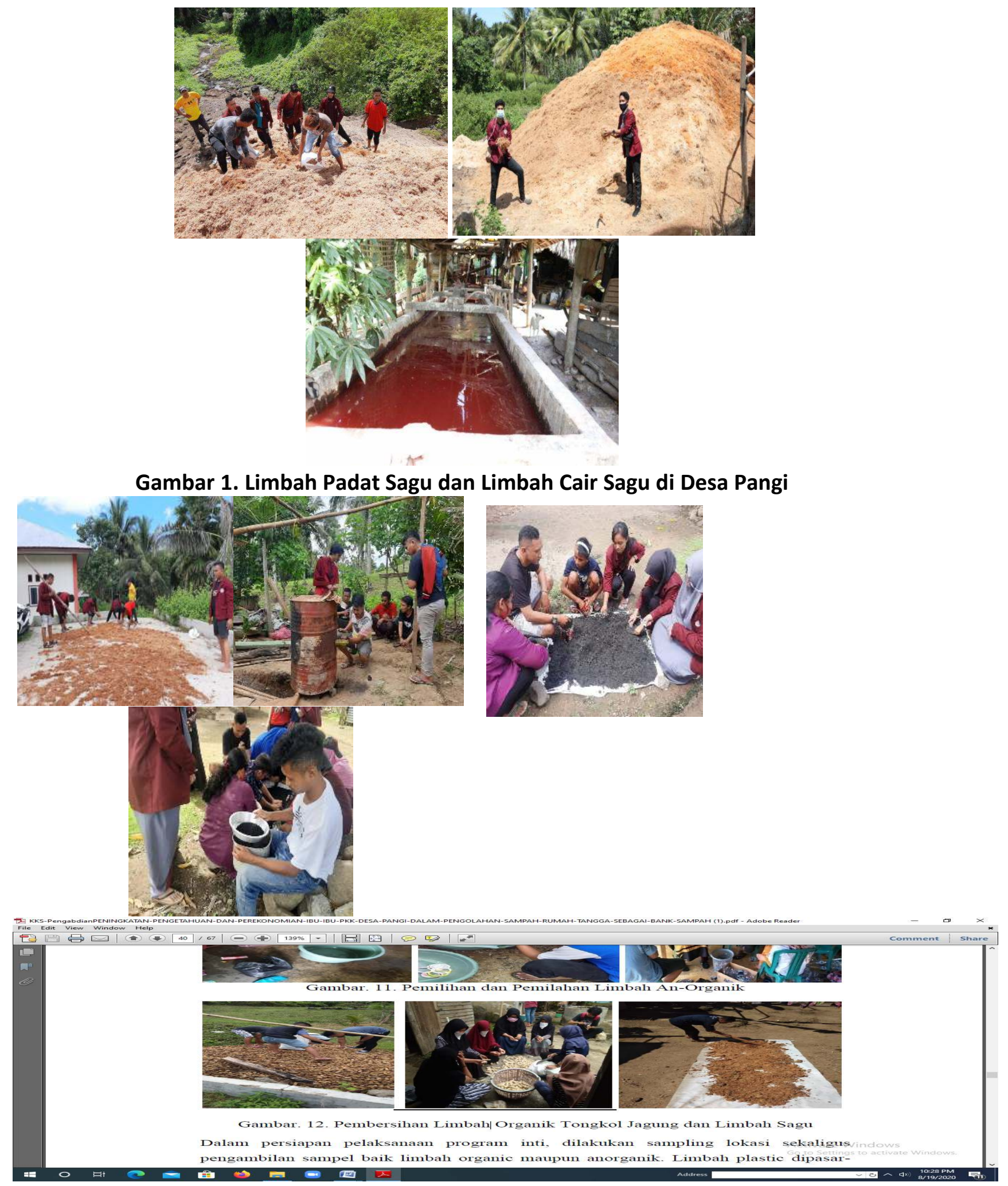

Gambar 2. Tahap Pembuatan Briket dari Ampas Sagu 


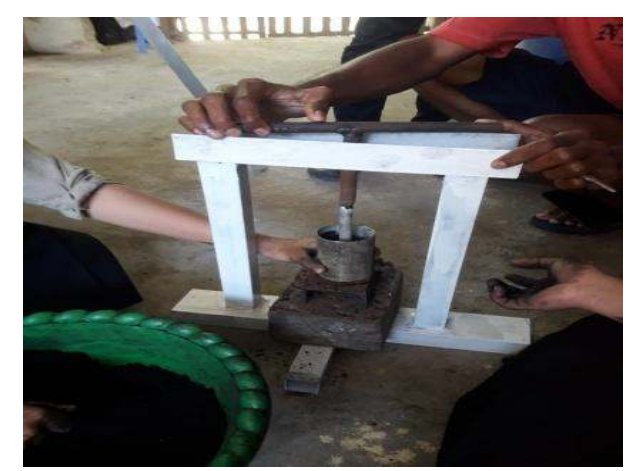

Gambar 3. Tahap Pencetakan Briket

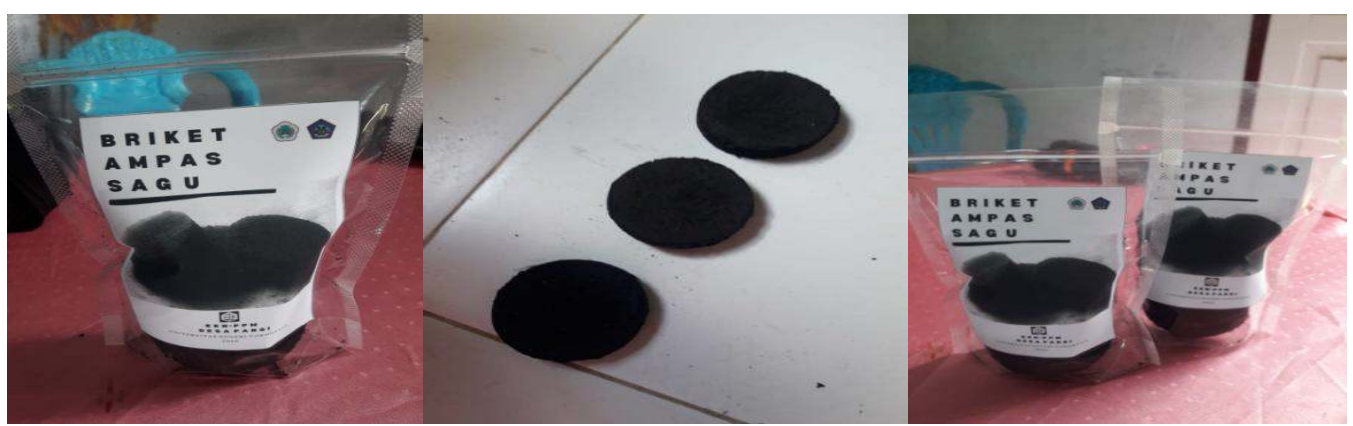

Gambar 4. Produk Briket yang Dihasilkan
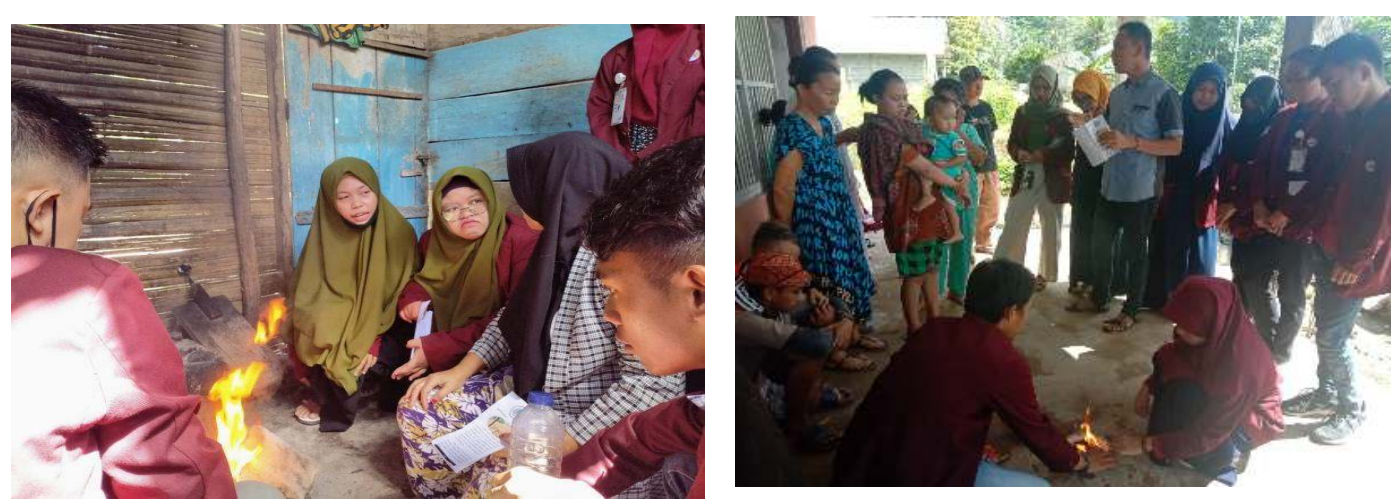

Gambar 5. Tahap Aplikasi Produk Briket yang Dihasilkan
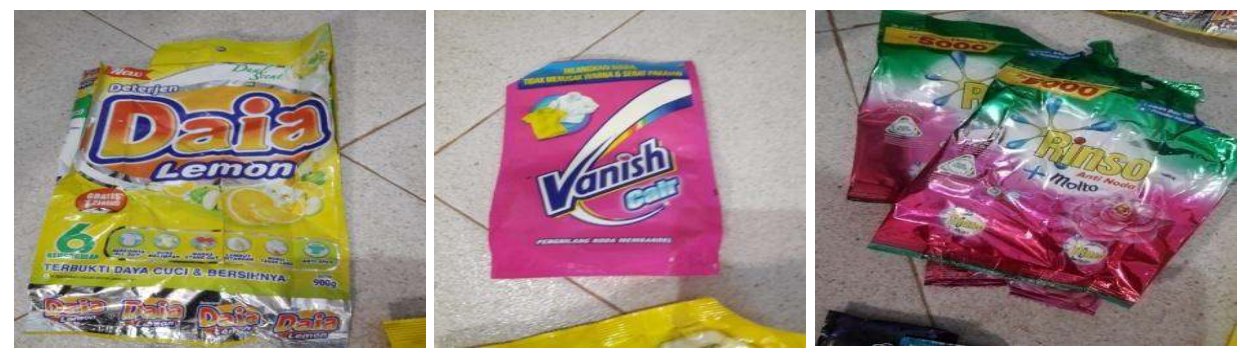

Gambar 6. Limbah Plastik Rumah Tangga 

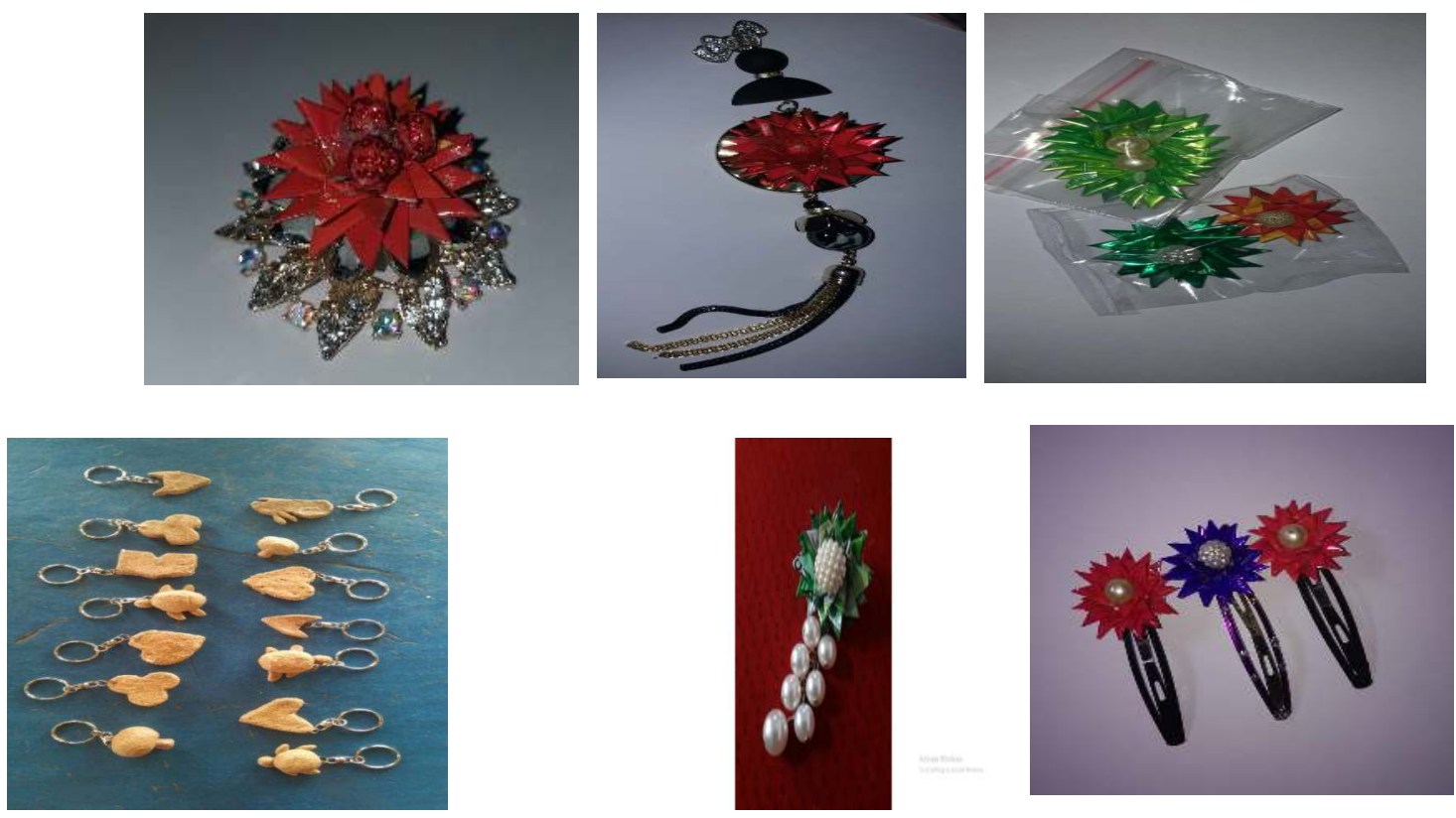

Gambar 7. Produk Kerajinan Tangan yang Dihasilkan PROSEDUR KERJA

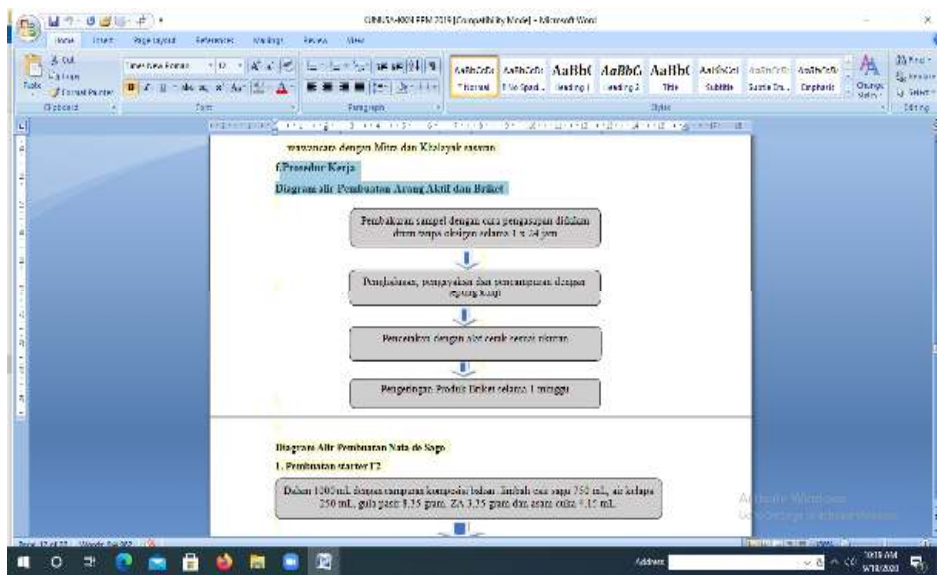

Gambar 8. Diagram alir Pembuatan Briket

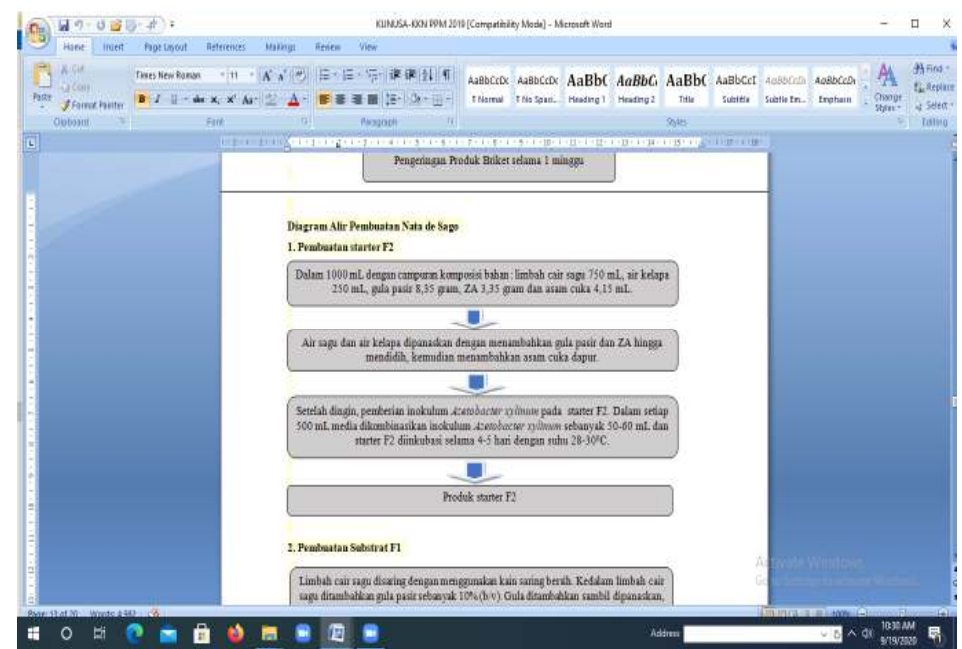

Gambar 9. Diagram Alir Pembuatan Nata de Sago 


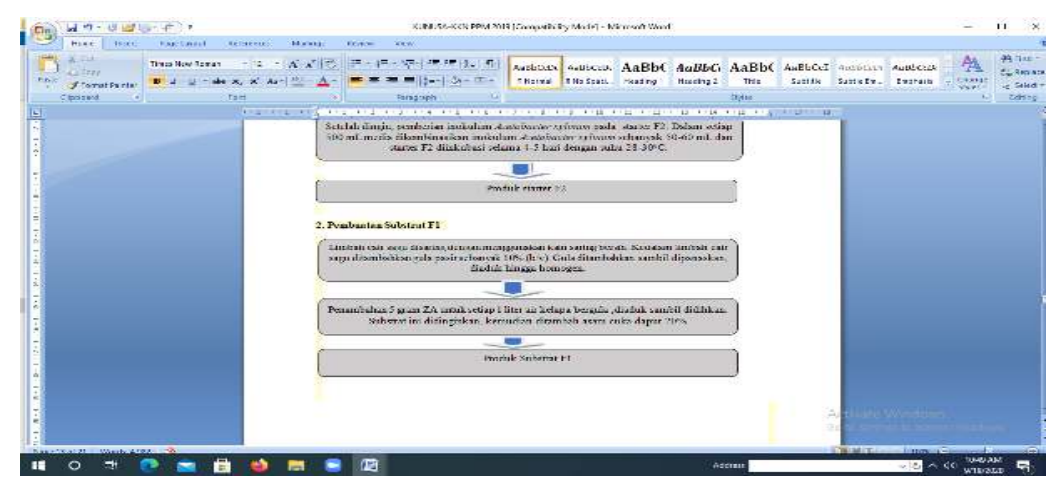

Gambar 10. Diagram Alir Pembuatan Substrat F1

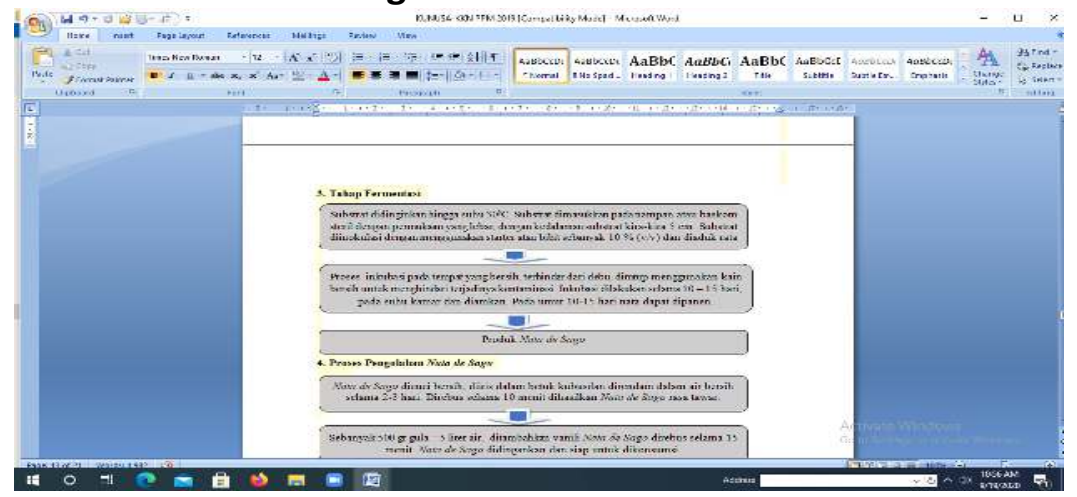

Gambar 11. Diagram Alir Tahap Fermentasi

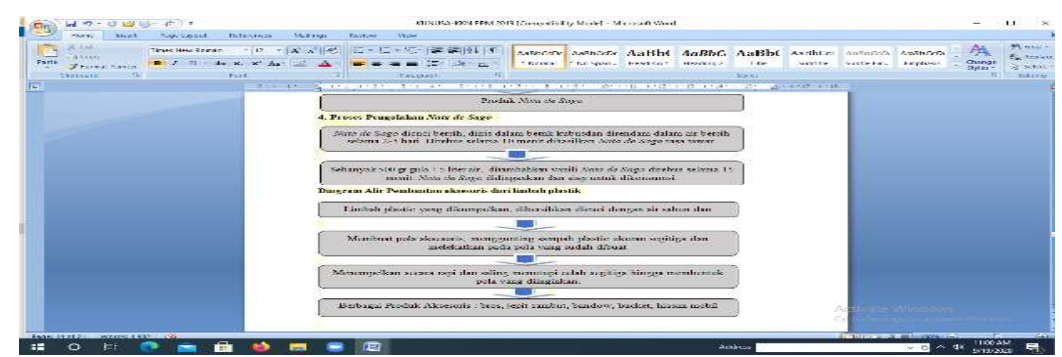

Gambar 12. Diagram Proses Pengolahan Nata de Sago

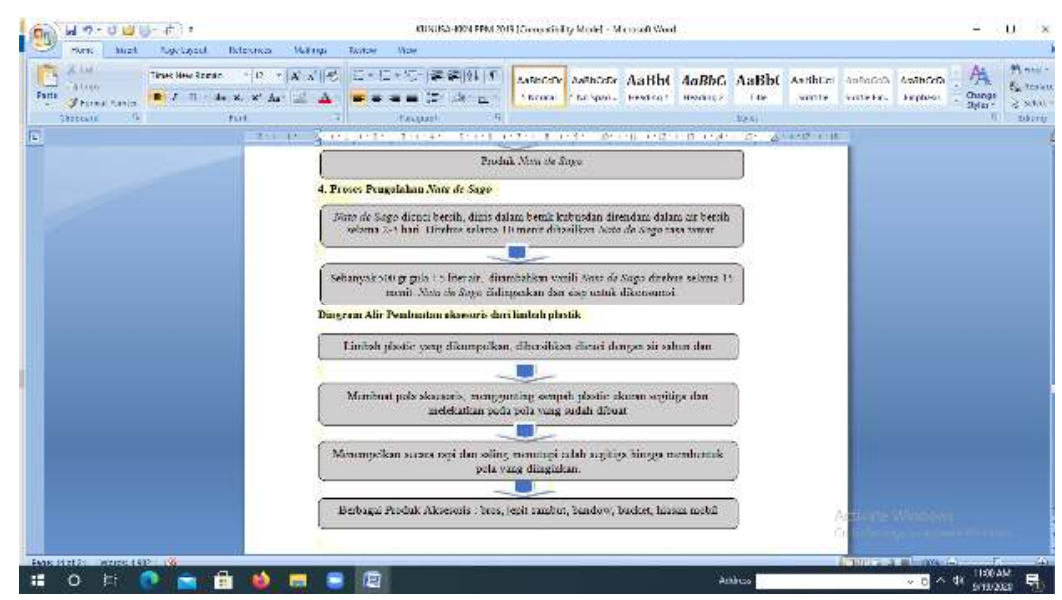

Gambar 13. Diagram Alir Pembuatan Aksesoris Limbah Plastik 


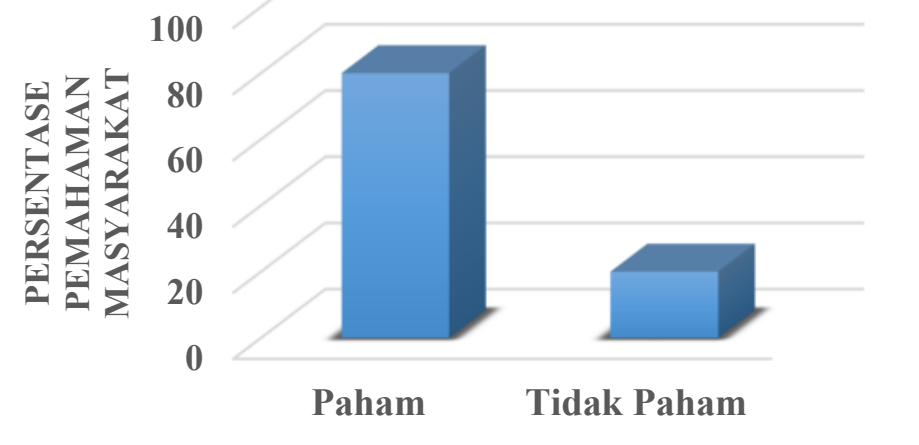

Gambar 14. Grafik Pemahaman Masyarakat 